\title{
Influence of Silk Fibroin Content on Cellulose Blend Film Using LiBr Solution
}

\author{
Jiwook Yang, , Gu-Joong Kwon, ${ }^{\mathrm{b}}$ Kyojung Hwang, ${ }^{\mathrm{a}}$ Jihui Byeon, ${ }^{\mathrm{a}}$ Gajanan S. Ghodake, \\ Surendra K. Shinde, ${ }^{a}$ Seunghun Hyun, ${ }^{c}$ and Dae-Young Kim ${ }^{\mathrm{a}, *}$ \\ Cellulose-silk fibroin (CSF) films were prepared by blending cellulose and \\ silk fibroin (SF) in different ratios (10:0, 10:3, 10:6, 10:9, and 10:12 wt\%) \\ in $60 \% \mathrm{LiBr}$ aqueous solution. All of the blend films were transparent, and \\ their coloration gradually increased with increasing SF content. \\ Interestingly, cross-sections of all of the tested films were observed by \\ scanning electron microscopy and exhibited similar morphologies. The silk \\ II structure was not well developed in the CSF; however, regenerated SF \\ affected the crystal structure of the cellulose and formed intermolecular \\ hydrogen bonds with cellulose. EDS mapping showed that cellulose and \\ silk in the film were distributed uniformly. The mechanical properties of the \\ dry-state film was greatly improved with the addition of an appropriate \\ amount of SF. In contrast with the dry-state films, the films in the wet state \\ exhibited smaller tensile strengths and E-modulus as SF content \\ increased; however, the elongation values were higher than those in the \\ dry-state films.
}

Keywords: Cellulose; Silk fibroin; Blend; Film

Contact information: a: Department of Biological and Environmental Science, Dongguk University, Biomedical Campus, Goyang-si, Ilsandong-gu 10326, Korea; b: The Institute of Forest Science, Kangwon National University, Chuncheon Campus, 1 Gangwondaehakgil, Chuncheon-si, Gangwon-do. 24341, South Korea; c: Division of Environmental Science and Ecological Engineering, Korea University, Seoul, 02841, Korea; *Corresponding author: sbpkim@dongguk.edu

\section{INTRODUCTION}

Cellulose is one of the most abundant natural polymers, occurring in plants, animals, algae, fungi, and bacteria. It consists of $\beta-(1 \rightarrow 4)$-linked glucose repeating units and is insoluble in water and common organic solvents because of strong inter- and intramolecular hydrogen bonding. In addition, it has numerous advantageous properties, including hydrophilicity, good thermal resistance, high mechanical strength, excellent biocompatibility, renewability, and biodegradability. Thus, cellulose and its derivatives have been used in a broad range of products (e.g., fibers, paper, filters, films, polymers, textiles, and food) (Klemm et al. 2005; Feng and Chen 2008; Lindman et al. 2010; Chang and Zhang 2011; Zhou et al. 2013; Yang et al. 2014). In addition, polymer blends have been developed to make cellulose more diverse and effective. The blending of polymers is an effective approach to combining the advantages of each component. In the case of cellulose, research is being conducted on blending with various polymers (e.g., collagen, chitosan, starch, silk, and protein) to improve or achieve certain physical or chemical properties (e.g., physicochemical or thermomechanical properties) and/or biological responses (Sionkowska 2011; Zhou et al. 2013).

Silk fibroin (SF) is as well known as cellulose and has been studied in the environmental materials and biotechnology fields. Silk is a natural protein-polymer 
produced by silkworms and spiders. It is composed of two proteins: SF and sericin. SF is a hydrophobic protein and the structural protein of fibers. Sericin is a hydrophilic glue-like protein and wraps around SF. SF has two main structures: silk I and silk II. The silk I structure comprise an unordered structure and a random-coil structure, whereas silk II is a $\beta$-sheet structure. In addition, silk and silk-based materials are used in biomedical applications (e.g., drug delivery, tissue engineering, wound dressing, enzyme immobilization matrices, structural implants, and bone tissue scaffolds) because of their excellent mechanical properties, biocompatibility, and biodegradability (Cao and Wang 2009; Bhardwaj and Kundu 2011; Dou and Zuo 2015; Qi et al. 2017; Tian et al. 2017).

Cellulose-silk fibroin (CSF) blending has been investigated as a method to improve the properties of polymers and has been applied in numerous fields. Marsano et al. (2008) made CSF blend fibers by using $N$-Methyl-morpholine $N$-oxide $\left(\mathrm{NMNO} / \mathrm{H}_{2} \mathrm{O}\right)$. Phase separation was observed in fibers of whole blends compositions, but the tensile properties implied good compatibility between cellulose and silk fibroin. $N, N$-dimethylacetamide (DMAc)/LiCl was used as a solvent for CSF blend fibers (Marsano et al. 2007). DMAc/LiCl did not cause degradation of the polymers. The homogenous blend fiber with good mechanical properties was observed, with no phase separations. Ionic liquids (IL) also were found to be a solvent to prepare cellulose-silk fibroin blend materials. ILs are considered green solvents due to their features such as non-flammability, low vapor pressure, thermal stability, and high reaction rates (Feng and Chen 2008; Shang et al. 2011; Yao et al. 2014). Zhou et al. (2013) prepared CSF blend films using 1-butyl-3methylimidazolium chloride $([\mathrm{BMIM}] \mathrm{Cl})$, one kind of ILs, as a solvent. The blend films had a good mechanical performance in both dry and wet states. Mouse fibroblast L929 cells were found to show significant adhesion and proliferation. The CSF blend fibers were fabricated with dry-jet wet spinning with [BMIM]Cl. The tensile strengh of the fibers contain $35 \mathrm{wt} \%$ silk fibroin was up to $191 \mathrm{MPa}$, although the tensile strength and initial modulus of blend fibers decreased with increasing silk fibroin content (Yao et al. 2015). However, these solvent systems suffer from some drawbacks such as low dissolving capability, instability, toxicity, difficulty in recycling (Feng and Chen 2008; Zhang et al. 2017).

Yang et al. (2014) developed a lithium bromide aqueous solution process for the dissolution-regeneration of cellulose. Cellulose is dissolved by heating in the solution. In this method, the dissolved cellulose is then regenerated by cooling and removing the salts with water. Recently, Kim et al. (2017) and others prepared cellulose-silk hydrogel by using the $\mathrm{LiBr}$ solution as a solvent. It was confirmed that $\mathrm{LiBr}$ solution can dissolve both cellulose and silk, and that CSF hydrogel would be useful in a variety of biomaterials applications.

The purpose of the present study was to prepare CSF blend films with various cellulose-to-SF ratios using an aqueous $\mathrm{LiBr}$ solution as a solvent. The physical and chemical properties were analyzed to determine the effect of SF on the properties of the cellulose blend films prepared using LiBr solution.

\section{EXPERIMENTAL}

\section{Materials}

Cocoons of Bombyx mori (Chunzam Bio Co., Ltd., Seoul, South Korea) were degummed by boiling in $0.5 \%(\mathrm{w} / \mathrm{w})$ aqueous $\mathrm{Na}_{2} \mathrm{CO}_{3}$ solution for $60 \mathrm{~min}$. The degummed 
silk fiber was washed and dried at $60{ }^{\circ} \mathrm{C}$ for $24 \mathrm{~h}$. $\alpha$-Cellulose powder was purchased from Sigma-Aldrich (St. Louis, MO, USA). LiBr (Samchun, Pure Chemical Co., Ltd., Seoul, South Korea) was used as a solvent for both SF and cellulose.

\section{Preparation of the CSF Composite Film}

Various amounts $(0,0.3,0.6,0.9$, and $1.2 \mathrm{~g})$ of SF were dissolved in $10 \mathrm{~g}$ of 60 $\mathrm{wt} \% \mathrm{LiBr}$ solutions at $70{ }^{\circ} \mathrm{C}$ for $4 \mathrm{~h}$. One gram of cellulose powder was dissolved in $89 \mathrm{~g}$ of $60 \mathrm{wt} \% \mathrm{LiBr}$ solution at $145{ }^{\circ} \mathrm{C}$ for $5 \mathrm{~min}$. The SF solution was added to the cellulose solution and mixed thoroughly for $2 \mathrm{~min}$. The cellulose-to-SF weight ratios was 10:0, 10:3, 10:6, 10:9, or 10:12. The mixed solutions were cast onto a glass mold preheated to $100{ }^{\circ} \mathrm{C}$. The solutions formed gels upon cooling to room temperature. Regenerated CSF gels were washed with water for $24 \mathrm{~h}$. The CSF films were prepared by compressing the gels with $2.5 \mathrm{~kg}$ weights for $30 \mathrm{~min}$ and then drying at $105 \pm 1{ }^{\circ} \mathrm{C}$ for $24 \mathrm{~h}$. The CSF films with cellulose-to-SF ratios of 10:0, 10:3, 10:6, 10:9, and 10:12 are hereafter abbreviated as CSF0, CSF3, CSF6, CSF9, and CSF12, respectively.

\section{Characterization}

The cross-sectional morphology of the CSF films was characterized by scanning electron microscopy (EM-30 Mini SEM, COXEM Co., Ltd., Daejeon, South Korea). The CSF gels $(10 \mathrm{~mm} \times 10 \mathrm{~mm})$ were cut using a microtome blade S-35 after the solvent exchange process (water $\rightarrow$ ethanol $\rightarrow$ t-butyl alcohol) and freeze-dried. The dried film samples were fractured in liquid nitrogen to investigate their internal morphological structure. X-ray diffraction (XRD) patterns of the CSF films were obtained with multipurpose X-ray diffractometer (X'Pert Pro MPD, PANalytical, Netherlands). The infrared spectra of the CSF films were recorded using a Fourier transform infrared (FTIR) spectrometer (Vertex70, Bruker Optics Ltd., Billerica, MA, USA). Elemental mapping analysis was performed using an energy-dispersive X-ray spectroscopy (EDS) analyzer (X Flash Detector 410-M, Bruker, Berlin, Germany). The mechanical properties of the CSF films $(15 \mathrm{~mm} \times 60 \mathrm{~mm} \times 0.04 \mathrm{~mm})$ were measured using a universal testing machine $(\mathrm{TO}-$ 102D, Test One, Siheung-si, Korea), and the experiment was repeated three times for validity and reliability in obtaining the results. The mechanical properties of the films were measured in both dry and wet states. The wet state film was immersed in water for 30 minutes, then excess water was removed and stored in a polypropylene bag.

\section{RESULTS AND DISCUSSION}

\section{Morphology of CSF Films}

Figure 1 shows photos of the CSF films and SEM images of the cross-sections of the gel before drying and those of dried films prepared with cellulose-to-SF ratios of 10:0, 10:3, 10:6, 10:9, and 10:12. All of the blend films were transparent, and the letters behind were visible. With increasing SF content, the coloration of the films gradually increased. The internal structure of the gels before film drying was porous, and network structures were observed. As the SF content was increased, the size of pores inside the gel gradually decreased and the structure became more complex and thicker. However, all of the crosssections of the films exhibited a similar shape. 


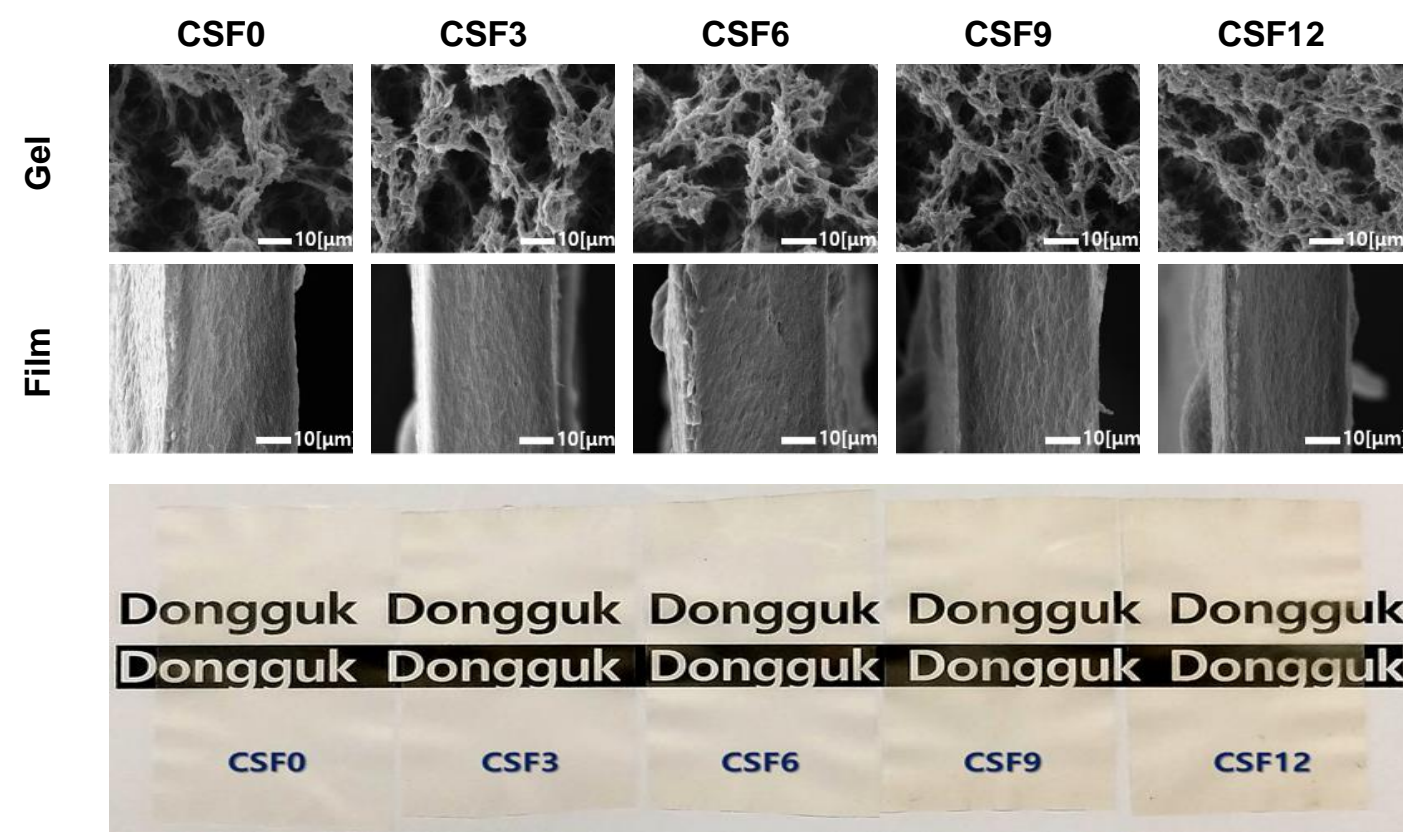

Fig. 1. Photos and SEM images of cross-sections of the gels before drying and cross-sections of the dried CSF films $(2,500 \times)$.

\section{XRD Analysis}

The XRD patterns of the CSF films are shown in Fig. 2. In the pattern of SF, diffraction peaks at $11.7^{\circ}$ (silk I), $19.7^{\circ}$ (silk I), $24.2^{\circ}$ (silk II), and $28.2^{\circ}$ (silk I) are observed, indicating that regenerated SF formed in both the silk I and silk II structures after dissolution and regeneration ( $\mathrm{Li}$ et al. 2001; Chen et al. 2012; Zhang et al. 2013; Wang et al. 2019). The XRD pattern of the CSF0 shows two peaks at $2 \theta=20.2^{\circ}$ and $22.8^{\circ}$, characteristic of the XRD pattern of regenerated cellulose, indicating that the crystalline structure of cellulose transformed from cellulose I to cellulose II (Cheng et al. 2012; Zhou et al. 2013; Yang et al. 2014). The XRD patterns of CSF3, CSF6, CSF9, and CSF12 were the same as that of CSF0, which was dominated by the characteristic peaks of cellulose II. The diffraction peaks of SF at $11.7^{\circ}, 24.2^{\circ}$, and $28.2^{\circ}$ disappeared in the patterned of blend films because the silk was sufficiently evenly mixed during the process of mixing with cellulose. In addition, cellulose dissolved in LiBr solution at high temperatures gelled when cooled to approximately $80{ }^{\circ} \mathrm{C}$. This cooling time may not be sufficient for the dissolved SF to form the $\beta$-sheet structure. Also, SF was fixed by gelled cellulose; therefore, the crystallinity of the silk II structure was not well developed. The peak at $20.2^{\circ}$ in the pattern of CSF0 shifted to $20.4^{\circ}$ in the patterns of all of the SF blend films. In addition, the peak intensities in the patterns of the blend films other than CSF12 increased compared with those in the pattern of CSF0; the intensities in the pattern of CSF12 decreased. These results indicate that the SF content of the CSF films affected the crystal structure of the cellulose (Marsano et al. 2008; Cao and Wang 2009; Cheng et al. 2012; Zhou et al. 2013; Yang et al. 2014; Kim et al. 2017). 


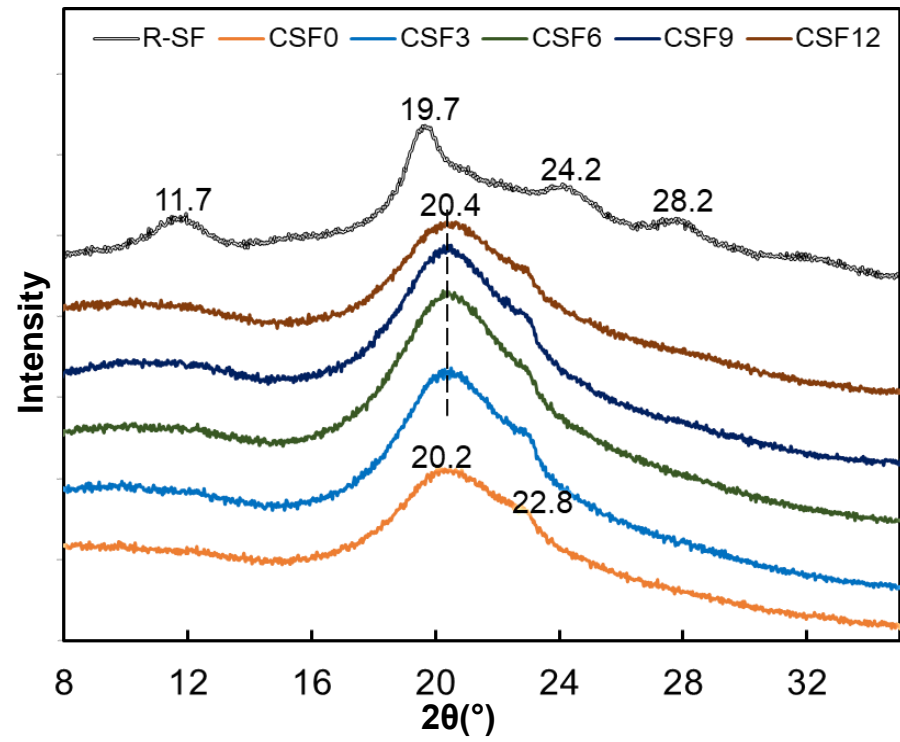

Fig. 2. X-ray diffraction patterns of the CSF films and regenerated silk fibroin (R-SF)

\section{FT-IR Analysis}

FT-IR spectroscopy was used to analyze the chemical changes in the CSF films as a function of the SF ratio. Figure 3 shows the FT-IR spectra of the CSF films and SF. The characteristic peaks in all CSF blend films observed at 898 ( $\beta$-glucosidic linkages between the glucose units), 1022 (C-O stretching vibration), 1155 (C-O-C antisymmetric bridge c$\mathrm{o}-\mathrm{c}$ stretching), and $1365 \mathrm{~cm}^{-1}$ ( $\mathrm{CH}$ bending), respectively, indicating presence of amorphous structures of cellulose (Kondo and Sawatari 1996; Oliveira Barud et al. 2015; Tian et al. 2017; Zhang et al. 2018). The spectra of the regenerated SF show an absorption band at $1638 \mathrm{~cm}^{-1}$ assigned to the random coil for amide $\mathrm{I}(\mathrm{C}=\mathrm{O}$ stretching). The absorption bands at $1515 \mathrm{~cm}^{-1}$ (amide II, secondary $\mathrm{NH}$ bending) and $1234 \mathrm{~cm}^{-1}$ (amide III, $\mathrm{C}-\mathrm{N}$ stretching) are assigned to the $\beta$-sheet structure (Yang et al. 2000; Ha et al. 2003; Lu et al. 2010; Li et al. 2017; Tian et al. 2017). These results indicate that the random coil and $\beta$ sheet structure coexist in the regenerated SF. However, the peak at $1515 \mathrm{~cm}^{-1}$ in the spectrum of the SF disappeared in the spectra of the blend films. The absorption peaks of amide $\mathrm{I}\left(1638 \mathrm{~cm}^{-1}\right)$ overlap the cellulose band at $1641 \mathrm{~cm}^{-1}$, which is assigned as the $\mathrm{OH}$ bending vibration of absorbed water, in addition, the intensity gradually increased with increasing SF content and a new peak appeared at $1739 \mathrm{~cm}^{-1}$ (Oh et al. 2005; Mohamed et al. 2016; Huang et al. 2017). These results indicate that the cellulose and SF interacted. The peak corresponding to $\mathrm{N}-\mathrm{H}$ groups $\left(3282 \mathrm{~cm}^{-1}\right)$ in the spectrum of SF disappeared, the broad band of cellulose at $3369 \mathrm{~cm}^{-1}$ (assigned to the $\mathrm{OH}$ groups) was shifted to lower wavenumbers, and the intensity of this broad band increased in the spectra of the blend films. These results reveal that intramolecular hydrogen bonds formed between the $\mathrm{OH}$ groups of cellulose and the NH groups of SF (Yang et al. 2000). 


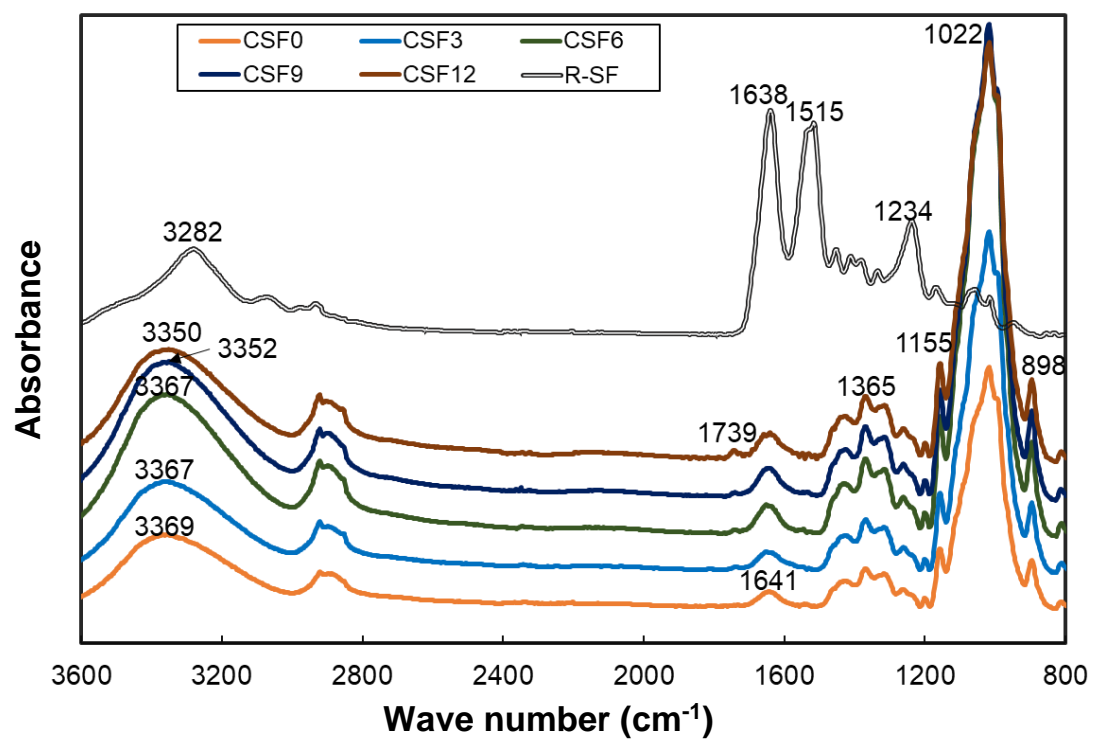

Fig. 3. FT-IR spectra of the CSF films and regenerated silk fibroin (R-SF)

\section{EDS mapping Analysis}

Based on the above results, element mapping of the distribution of carbon (C) and nitrogen $(\mathrm{N})$ on the surface of the CSF9 film using EDS was performed to ensure that cellulose and silk were evenly mixed in the film (Fig. 4). Carbon atoms in the film were elements contained in both cellulose and SF, and nitrogen atoms were unique to SF molecules and were used to identify the distribution of SF polymers. $\mathrm{N}$ was evenly distributed in the mapping image. In comparison with $\mathrm{C}, \mathrm{N}$ was detected at low concentrations since SF was the only source of $\mathrm{N}$ in the film. Therefore, the homogeneous dispersion of SF in CSF9 was confirmed, indicated cellulose and SF were uniformly mixed in the blend films.
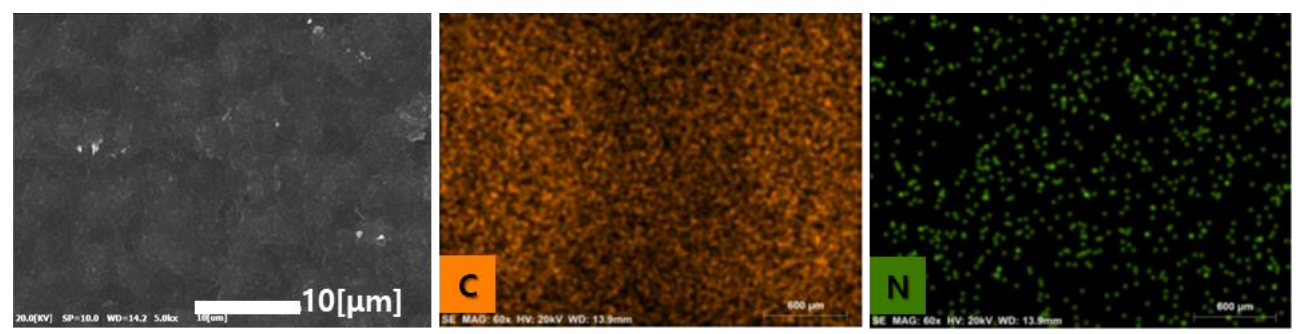

Fig. 4. EDS mapping images of carbon and nitrogen on CSF6 film surface

\section{Mechanical Analysis}

Table 1 shows the thickness of the CSF blend films in the both dry and wet state. The thickness of dry CSF0 composed of cellulose was $42.1 \pm 1.3 \mu \mathrm{m}$. It was slightly increased with increasing SF content. The thickness of wet CSF films also was slightly increased with increasing SF content. However, the difference between the thickness of the dry film and the wet film was about $19 \mu \mathrm{m}$ in all conditions, the water content of all films was about 45 to $46 \%$, and there was no difference depending on the SF content.

The tensile strength, elongation, and E-modulus were carried out to evaluate the mechanical properties of the CSF film, in both the dry state (Fig. 5) and the wet state (Fig. 
6). The tensile strength of the CSF0, CSF3, CSF6, CSF9, and CSF12 films was 84.6, 115.1, 123.9, 115.0, and 103.8 $\mathrm{MPa}$, respectively (Fig. 5a). The tensile strength reached a maximum at CSF6 and then decreased as the SF content was increased further. The elongation of the CSF0, CSF3, CSF6, CSF9, and CSF12 films was 3.7, 10.4, 11.7, 10.3, and $8.5 \%$, respectively (Fig. 5b). The elongation values increased to a maximum at CSF6, reaching three times the elongation of CSF0, and then decreased as the SF content was increased further. The E-modulus of the CSF0, CSF3, CSF6, CSF9, and CSF12 films was 3.30, 3.36, 3.52, 3.36, and 3.22 GPa, respectively (Fig. 5c). The trend of the films Emodulus was similar to the trends of the tensile strength and the elongation; however, the overall values did not substantially differ from each other. With the addition of SF, the mechanical properties of the blend films in the dry state improved, possibly because the cellulose and SF completely dissolved and uniformly blended in the $\mathrm{LiBr}$ solution system and because strong interactions such as hydrogen bonding between the two polymers remarkably enhanced the interfacial adhesion, which suggests that the cellulose network in the blend films was reinforced by SF (Shang et al. 2011; Yao et al. 2015). However, as the $S F$ ratio was increased further, the mechanical strength decreased.

The tensile strength of the CSF0, CSF3, CSF6, CSF9, and CSF12 films was 21.68, 19.1, 18.9, 18.4, and 14.0 MPa, respectively (Fig. 6a). The E-modulus of the CSF0, CSF3, CSF6, CSF9, and CSF12 specimens was 0.132, 0.094, 0.083, 0.079, and 0.079 GPa, respectively (Fig. 6c). Both the tensile strength and E-modulus of the CSF films in the wet state decreased with increasing silk content, unlike the results corresponding to the dry films. These results can be attributed to the water molecules absorbed into the films increasing the intermolecular distance and interfering with the interaction between the cellulose the and SF (Plaza et al. 2008; Adel et al. 2014). In addition, poor development of the silk II structure of SF apparently affects the physical strength of the film against water. The elongation of the CSF0, CSF3, CSF6, CSF9, and CSF12 films was 18.6, 19.5, 21.3, 22.7 , and $18.8 \%$, respectively (Fig. 6b). The elongation values reached a maximum at CSF9 and then decreased as the SF content was increased further. Compared with the results corresponded to the dry state, the results of the CSF films in the wet state show greater values and tend to be similar. Silk fiber has been shown to exhibit greater elasticity in the wet state than in the dry state (Plaza et al. 2008; Aytemiz et al. 2018). We propose that this property of SF influenced the properties of the wet CSF films.

Feng et al. (2017) prepared CNF-reinforced silk/cellulose composite films using $\mathrm{LiBr}$ aqueous solution as a solvent. The composite films showed a tendency to decrease both tensile strength and elongation with decreasing cellulose content and with increasing SF content. Compared with this study, SF seems to have a great effect on the mechanical strength enhancement in the blend films with a sufficient concentration of cellulose.

Table 1. Thickness of the CSF blend films in dry and wet state

\begin{tabular}{|c|c|c|c|c|c|}
\hline$(\mu \mathrm{m})$ & CSF0 & CSF3 & CSF6 & CSF9 & CSF12 \\
\hline Dry & $42.1 \pm 1.3$ & $44.7 \pm 1.5$ & $45.1 \pm 0.7$ & $45.2 \pm 1.0$ & $45.8 \pm 1.0$ \\
\hline Wet & $62.1 \pm 0.6$ & $64.3 \pm 1.5$ & $64.4 \pm 0.4$ & $64.8 \pm 1.5$ & $64.7 \pm 0.7$ \\
\hline
\end{tabular}



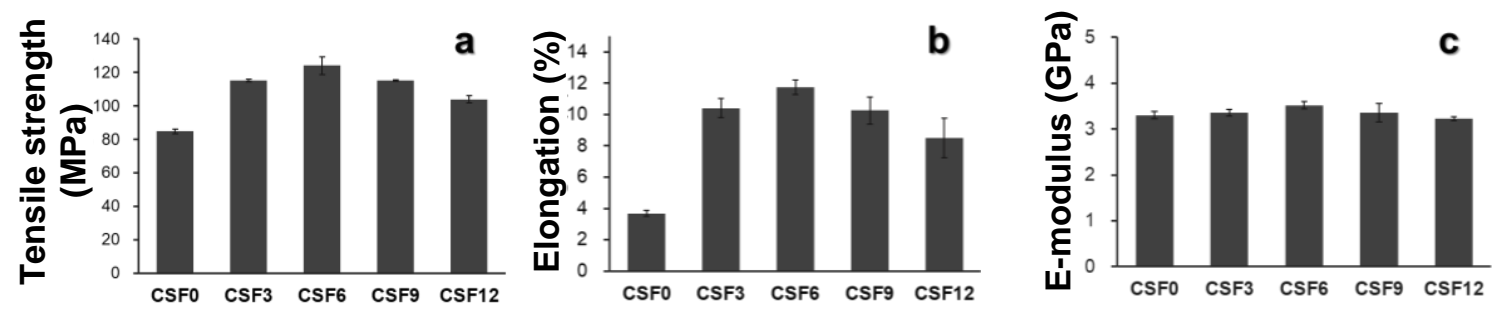

Fig. 5. Tensile strength (a), elongation (b), and E-modulus (c) of the CSF films in dry state
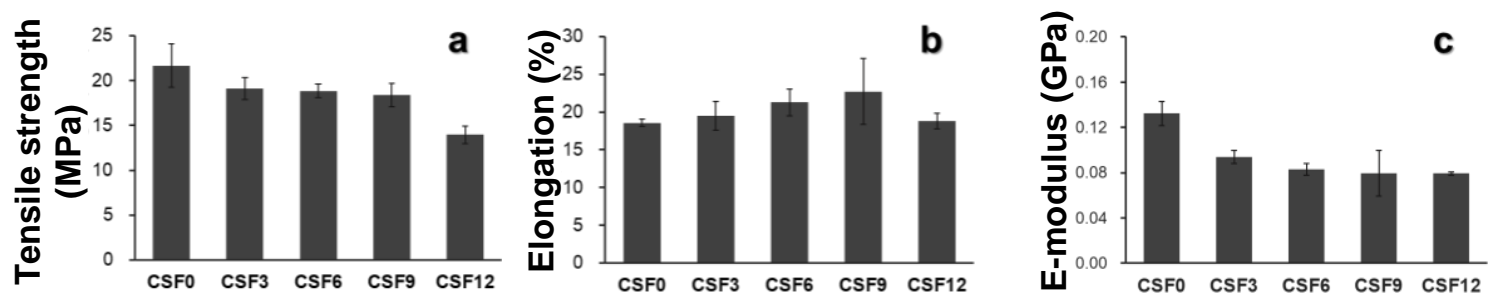

Fig. 6. Tensile strength (a), elongation (b), and E-modulus (c) of the CSF films in wet state

\section{CONCLUSIONS}

1. Cellulose-silk fibroin (CSF films) were prepared by dissolving and blending cellulose and silk fibroin (SF) in $60 \% \mathrm{LiBr}$ solution.

2. All of the resultant blend films were transparent, and the films tended to thicken gradually with increasing SF content.

3. The cross-sections of all of the tested films were observed to exhibit a similar shape and morphology.

4. The silk II structure was not well developed in the CSF films because of insufficient time to form the $\beta$-sheet structure of SF. However, regenerated SF affected the crystal structure of the cellulose in the films and formed intermolecular hydrogen bonds with cellulose.

5. EDS mapping analysis was confirmed that cellulose and SF were uniformly blended in the CSF films.

6. The mechanical properties of the dry CSF films were greatly improved with the addition of an appropriate amount of SF. In contrast with the dry state, the wet films in the wet state exhibited decreasing the tensile strength and E-modulus with increasing SF content, whereas their elongation values were higher than those in the dry state.

7. These results are expected to be useful knowledge for biomedical applications such as biomaterials, skin tissue engineering, and medical dressings. 


\section{ACKNOWLEDGMENTS}

This work was supported by the National Research Foundation of Korea (NRF) grant funded by the Korea government (MSIT) (No. NRF-2019R1A2C1007661).

\section{REFERENCES CITED}

Adel, A. M., Dupont, A.-L., Abou-Yousef, H., El-Gendy, A., Paris, S., and El-Shinnawy, N. (2014). "A study of wet and dry strength properties of unaged and hygrothermally aged paper sheets reinforced with biopolymer composites," Journal of Applied Polymer Science, 131(18), 9212-9224. DOI: 10.1002/app.40761

Aytemiz, D., Fukuda, Y., Higuchi, A., Asano, A., Nakazawa, C., Kameda, T., Yoshioka, T., and Nakazawa, Y. (2018). "Compatibility evaluation of non-woven sheet composite of silk fibroin and polyurethane in the wet state," Polymers 10(8), 874885. DOI: $10.3390 /$ polym 10080874

Bhardwaj, N., and Kundu, S. C. (2011). "Silk fibroin protein and chitosan polyelectrolyte complex porous scaffolds for tissue engineering applications," Carbohydrate Polymers, 85(2), 325-333. DOI: 10.1016/j.carbpol.2011.02.027

Cao, Y., and Wang, B. (2009). "Biodegradation of silk biomaterials," International Journal of Molecular Sciences 10(4), 1514-1524. DOI: 10.3390/ijms10041514

Chang, C., and Zhang, L. (2011). "Cellulose-based hydrogels: Present status and application prospects," Carbohydrate Polymers 84(1), 40-53. DOI: 10.1016/j.carbpol.2010.12.023

Chen, J.-P., Chen, S.-H., and Lai, G.-J. (2012). "Preparation and characterization of biomimetic silk fibroin/chitosan composite nanofibers by electrospinning for osteoblasts culture," Nanoscale Research Letters 7(1), 170. DOI: 10.1186/1556276X-7-170

Cheng, G., Varanasi, P., Arora, R., Stavila, V., Simmons, B. A., Kent, M. S., and Singh, S. (2012). "Impact of ionic liquid pretreatment conditions on cellulose crystalline structure using 1-ethyl-3-methylimidazolium acetate," The Journal of Physical Chemistry B 116(33), 10049-10054. DOI: 10.1021/jp304538v

Dou, H., and Zuo, B. (2015). "Effect of sodium carbonate concentrations on the degumming and regeneration process of silk fibroin," The Journal of The Textile Institute, 106(3), 311-319. DOI: 10.1080/00405000.2014.919065

Feng, L., and Chen, Z. (2008). "Research progress on dissolution and functional modification of cellulose in ionic liquids," Journal of Molecular Liquids, 142(1-3), 15. DOI: 10.1016/j.molliq.2008.06.007

Feng, Y., Li, X., Li, M., Ye, D., Zhang, Q., You, R., and Xu, W. (2017). "Facile preparation of biocompatible silk fibroin/cellulose nanocomposite films with high mechanical performance," ACS Sustainable Chemistry and Engineering 5(7), 62276236. DOI: 10.1021/acssuschemeng.7b01161

Ha, S.-W., Park, Y. H., and Hudson, S. M. (2003). "Dissolution of bombyx m ori silk fibroin in the calcium nitrate tetrahydrate-methanol system and aspects of wet spinning of fibroin solution," Biomacromolecules 4(3), 488-496. DOI: 10.1021/bm0255948 
Huang, Y., Bailey, K., Wang, S., and Feng, X. (2017). "Silk fibroin films for potential applications in controlled release," Reactive and Functional Polymers 116(May), 5768. DOI: 10.1016/j.reactfunctpolym.2017.05.007

Kim, H. J., Yang, Y. J., Oh, H. J., Kimura, S., Wada, M., and Kim, U.-J. (2017). "Cellulose-silk fibroin hydrogels prepared in a lithium bromide aqueous solution," Cellulose 24(11), 5079-5088. DOI: 10.1007/s10570-017-1491-7

Klemm, D., Heublein, B., Fink, H.-P., and Bohn, A. (2005). "Cellulose: Fascinating biopolymer and sustainable raw material," Angewandte Chemie International Edition 44(22), 3358-3393. DOI: 10.1002/anie.200460587

Kondo, T., and Sawatari, C. (1996). "A Fourier transform infra-red spectroscopic analysis of the character of hydrogen bonds in amorphous cellulose," Polymer 37(3), 393-399. DOI: 10.1016/0032-3861(96)82908-9

Li, M., Lu, S., Wu, Z., Yan, H., Mo, J., and Wang, L. (2001). “Study on porous silk fibroin materials. I. Fine structure of freeze dried silk fibroin," Journal of Applied Polymer Science 79(12), 2185-2191. DOI: 10.1002/10974628(20010321)79:12<2185::AID-APP1026>3.0.CO;2-3

Li, Q., Qi, N., Peng, Y., Zhang, Y., Shi, L., Zhang, X., Lai, Y., Wei, K., Kim, I. S., and Zhang, K. Q. (2017). "Sub-micron silk fibroin film with high humidity sensibility through color changing," RSC Advances 7(29), 17889-17897. DOI: $10.1039 / \mathrm{c} 6 \mathrm{ra} 28460 \mathrm{~d}$

Lindman, B., Karlström, G., and Stigsson, L. (2010). "On the mechanism of dissolution of cellulose," Journal of Molecular Liquids 156(1), 76-81. DOI: 10.1016/j.molliq.2010.04.016

Lu, Q., Hu, X., Wang, X., Kluge, J. A., Lu, S., Cebe, P., and Kaplan, D. L. (2010). "Water-insoluble silk films with silk I structure," Acta Biomaterialia 6(4), 13801387. DOI: 10.1016/j.actbio.2009.10.041

Marsano, E., Canetti, M., Conio, G., Corsini, P., and Freddi, G. (2007). "Fibers based on cellulose-silk fibroin blend,” Journal of Applied Polymer Science, 104(4), 21872196. DOI: 10.1002/app.24856

Marsano, E., Corsini, P., Canetti, M., and Freddi, G. (2008). "Regenerated cellulose-silk fibroin blends fibers," International Journal of Biological Macromolecules 43(2), 106-114. DOI: 10.1016/j.ijbiomac.2008.03.009

Mohamed, M. A., W. Salleh, W. N., Jaafar, J., Ismail, A. F., Mutalib, M. A., Sani, N. A. A., M. Asri, S. E. A., and Ong, C. S. (2016). "Physicochemical characteristic of regenerated cellulose/N-doped $\mathrm{TiO}_{2}$ nanocomposite membrane fabricated from recycled newspaper with photocatalytic activity under UV and visible light irradiation," Chemical Engineering Journal 284, 202-215. DOI: 10.1016/j.cej.2015.08.128

Oh, S. Y., Yoo, D. Il, Shin, Y., and Seo, G. (2005). "FTIR analysis of cellulose treated with sodium hydroxide and carbon dioxide," Carbohydrate Research 340(3), 417428. DOI: 10.1016/j.carres.2004.11.027

Oliveira Barud, H. G., Barud, H. D. S., Cavicchioli, M., Do Amaral, T. S., De Oliveira Junior, O. B., Santos, D. M., De Oliveira Almeida Petersen, A. L., Celes, F., Borges, V. M., De Oliveira, C. I., De Oliveira, P. F., Furtado, R. A., Tavares, D. C., and Ribeiro, S. J. L. (2015). "Preparation and characterization of a bacterial cellulose/silk fibroin sponge scaffold for tissue regeneration," Carbohydrate Polymers 128, 41-51. DOI: 10.1016/j.carbpol.2015.04.007 
Plaza, G. R., Corsini, P., Pérez-Rigueiro, J., Marsano, E., Guinea, G. V., and Elices, M. (2008). "Effect of water on Bombyx mori regenerated silk fibers and its application in modifying their mechanical properties," Journal of Applied Polymer Science 109(3), 1793-1801. DOI: 10.1002/app.28288

Qi, Y., Wang, H., Wei, K., Yang, Y., Zheng, R.-Y., Kim, I., and Zhang, K.-Q. (2017). “A review of structure construction of silk fibroin biomaterials from single structures to multi-level structures," International Journal of Molecular Sciences 18(3), 237-257. DOI: 10.3390/ijms18030237

Shang, S., Zhu, L., and Fan, J. (2011). "Physical properties of silk fibroin/cellulose blend films regenerated from the hydrophilic ionic liquid," Carbohydrate Polymers 86(2), 462-468. DOI: 10.1016/j.carbpol.2011.04.064

Sionkowska, A. (2011). "Current research on the blends of natural and synthetic polymers as new biomaterials: Review," Progress in Polymer Science (Oxford) 36(9), 1254-1276. DOI: 10.1016/j.progpolymsci.2011.05.003

Tian, D., Li, T., Zhang, R., Wu, Q., Chen, T., Sun, P., and Ramamoorthy, A. (2017). "Conformations and Intermolecular interactions in cellulose/silk fibroin blend films: A solid-state NMR perspective," Journal of Physical Chemistry B 121(25), 61086116. DOI: 10.1021/acs.jpcb.7b02838

Wang, B., Zhang, S., Wang, Y., Si, B., Cheng, D., Liu, L., and Lu, Y. (2019). "Regenerated Antheraea pernyi silk fibroin/poly(n-isopropylacrylamide) thermosensitive composite hydrogel with improved mechanical strength," Polymers 11(2), 302-316. DOI: 10.3390/polym11020302

Yang, G., Zhang, L., and Liu, Y. (2000). "Structure and microporous formation of cellulose/silk fibroin blend membranes," Journal of Membrane Science 177(1-2), 153-161. DOI: 10.1016/S0376-7388(00)00467-1

Yang, Y.-J., Shin, J.-M., Kang, T. H., Kimura, S., Wada, M., and Kim, U.-J. (2014). "Cellulose dissolution in aqueous lithium bromide solutions," Cellulose 21(3), 11751181. DOI: $10.1007 / \mathrm{s} 10570-014-0183-9$

Yao, Y., Mukuze, K. S., Zhang, Y., and Wang, H. (2014). "Rheological behavior of cellulose/silk fibroin blend solutions with ionic liquid as solvent," Cellulose 21(1), 675-684. DOI: 10.1007/s10570-013-0117-y

Yao, Y., Zhang, E., Xia, X., Yu, J., Wu, K., Zhang, Y., and Wang, H. (2015). "Morphology and properties of cellulose/silk fibroin blend fiber prepared with 1butyl-3-methylimidazolium chloride as solvent," Cellulose 22(1), 625-635. DOI: 10.1007/s10570-014-0520-Z

Zhang, J., Wu, J., Yu, J., Zhang, X., He, J., and Zhang, J. (2017). “Application of ionic liquids for dissolving cellulose and fabricating cellulose-based materials: State of the art and future trends," Materials Chemistry Frontiers 1(7), 1273-1290. DOI: 10.1039/c6qm00348f

Zhang, Q., Li, M., Xu, W., Li, J., and Yan, S. (2013). “A novel silk fibroin scaffolds with oriented multichannels," Materials Letters 105, 8-11. DOI:

10.1016/j.matlet.2013.04.049 
Zhang, X., Xiao, N., Wang, H., Liu, C., and Pan, X. (2018). "Preparation and characterization of regenerated cellulose film from a solution in lithium bromide molten salt hydrate," Polymers 8(6). DOI: 10.3390/polym10060614

Zhou, L., Wang, Q., Wen, J., Chen, X., and Shao, Z. (2013). "Preparation and characterization of transparent silk fibroin/cellulose blend films," Polymer 54(18), 5035-5042. DOI: 10.1016/j.polymer.2013.07.002

Article submitted: November 11, 2019; Peer review completed: January 15, 2020;

Revisions accepted: February 11, 2020; Published: February 12, 2020.

DOI: 10.15376/biores.15.2.2459-2470 